\title{
An Experimenter's Experiences in Early Commercial Suborbital Flight
}

Steven H. Collicott

School of Aeronautics and Astronautics, Purdue University, West Lafayette, IN

\begin{abstract}
The emerging commercial suborbital rocket industry in the U.S. presents new opportunities for research and education missions. Some companies have been publicized by the world's media and others are lower-profile. Additionally, some companies were created for the space tourism market and others have no current plans to fly humans at all. Most companies already have a Payload User's Guide published at their websites. The time for experimenters to take note of this industry is now, because in early 2014 a number of these companies were already operational or in flight test phase of their business development. When thousands of dollars, instead of millions for traditional NASA or European Space Agency (ESA) sounding rockets, are needed for a suborbital flight, many more researchers will be able to afford suborbital testing and research. In general, these rocket companies seek to provide at least three minutes of high-quality weightless test times from approximately $60 \mathrm{~km}$ to $100 \mathrm{~km}$ in altitude, and back to $60 \mathrm{~km}$. Purdue University has been fortunate to have secured numerous launches for small payloads during these developmental
\end{abstract}

Key words: $\quad$ Suborbital; Rocket; Experiment; Spaceport

Correspondence to Steven H. Collicott

701 West Stadium Avenue

West Lafayette, IN 47907-2045

Telephone: 765-494-2339

E-mail: collicott@purdue.edu and early operational years of the industry. Lessons from these launches include lessons in design, payload environment, procedures, launch site infrastructure, and travel preparations.

\section{INTRODUCTION}

The next-generation commercial suborbital rocket industry (Stern, 2013) is presently a collection of companies that are in or nearing flight testing. Several of the companies have sought to develop experience with research customers during their flight test program, as shown in Figure 1. Eventually it is expected that spaceports and flight providers will be experienced and well-equipped for supporting researchers at the launch sites, but at present early researchers are themselves, in effect, experiments for the spaceports and vehicle providers. The author has been fortunate to be involved in a number of these collaborations (Collicott, 2011) and seeks to relate lessons learned so as to benefit other early research participants. No statement below is a criticism of vehicle providers or spaceports; rustic or simplistic research infrastructure and procedures are simply the state of the industry when the most important achievement is getting the vehicle tested and flying.

All but one of the Purdue payloads are designed and built by undergraduate aerospace engineering students in the author's class, AAE418 "Zero-gravity Flight Experiments." Since NASA's first nationwide collegiate Reduced Gravity Student Flight Opportunity 
Program in 1996, students in the School of Aeronautics and Astronautics in the College of Engineering at Purdue University have designed, built, and flown 36 original student-operated parabolic aircraft flight experiments, more than 10 automated suborbital payloads, and in 2012 NASA selected this program for one studentdesigned experiment that was under construction for the International Space Station (ISS), but is now canceled by NASA.

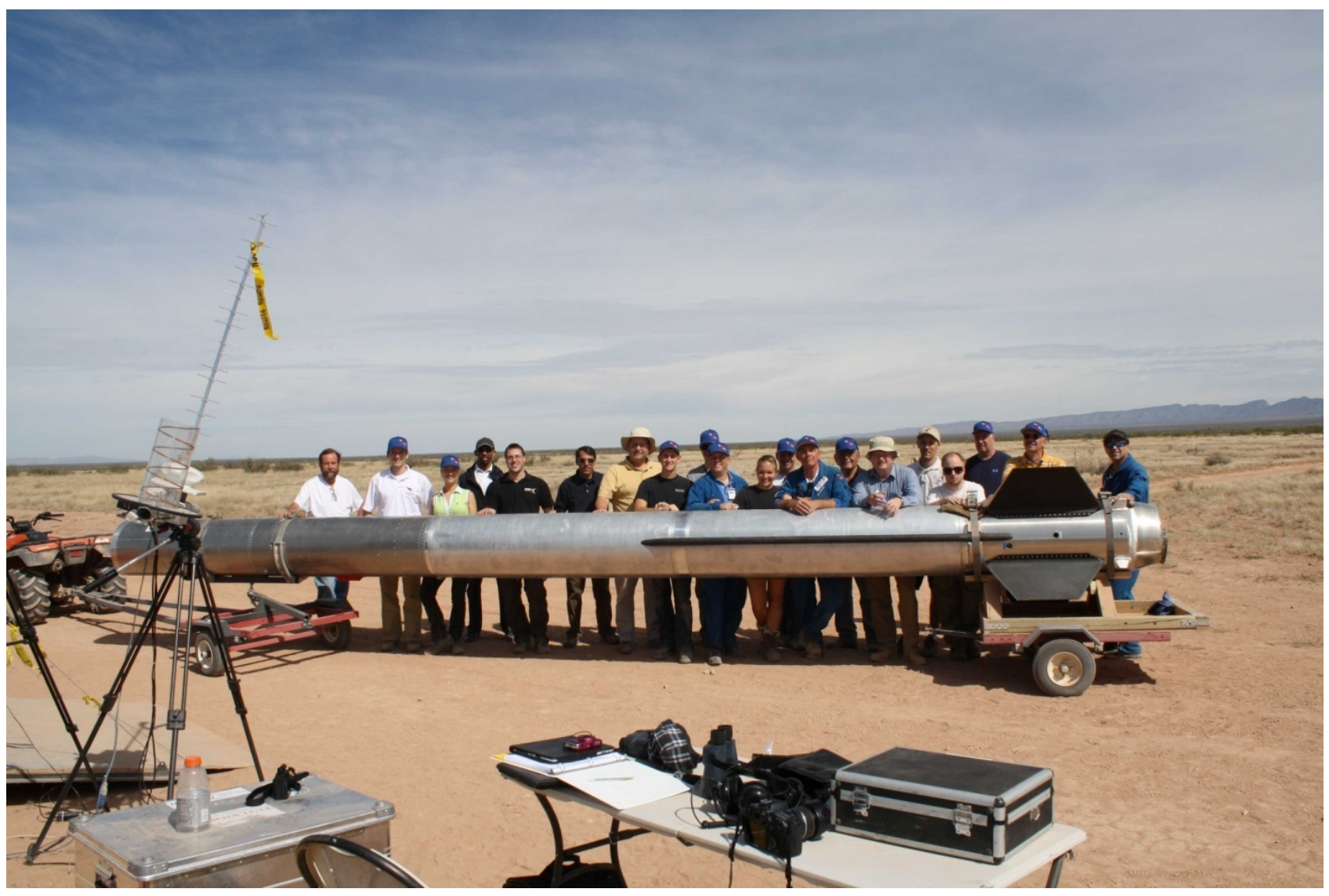

Figure 1. Launch team and two teams of researchers in the commercial suborbital industry with Armadillo's STIG-B rocket. This was after a gentle, on target, parachute landing following an Armadillo launch that aborted safely on ascent. The blue baseball hats commemorate the first licensed commercial suborbital launch at New Mexico Spaceport America on October 10, 2012.

\section{G-LEVELS}

Suborbital flight to $100 \mathrm{~km}$ does not place the payload "above the atmosphere." Of course, there is no distinct altitude at which one is above the atmosphere, but flights in the near future will provide access to the mesosphere and lower thermosphere, up to approximately $100 \mathrm{~km}$. This is above much of the atmosphere so, for example, infrared astronomers may see new opportunities as the flight path is above even more of the water vapor than a Stratospheric Observatory for Infrared Astronomy (SOFIA) aircraft flight. Others may have to accommodate the fact that aerodynamic drag remains non-zero, thereby potentially affecting microgravity physics experiments.

Drag can be estimated from a standard atmosphere, basic physics, assumed mass, and assumptions of a drag coefficient based on shape and orientation. Vehicle providers advertise approximately three minutes of coasting flight, 
with apogee at $100 \mathrm{~km}$. Basic physics shows that, therefore, the coast begins at $60 \mathrm{~km}$. The greatest drag is present at the $60 \mathrm{~km}$ altitude because this is where both the vehicle velocity (approximately Mach 3) and air density are the greatest. Depending on assumptions of mass and shape (drag coefficient), a range of 0.5 to 5 milli-g appears to be the range to expect. Any horizontal component of the flight velocity, which might vary significantly between the different styles of vehicles being developed for this market, will increase these $g$-level estimates.

Microgravity fluids experiment design can often accommodate the drag by both orienting the experiment so that this small acceleration due to drag pushes the liquid into a desired location, such as one end of a test vessel, and by modeling the fluids beforehand with the acceleration included. In general, seeking design advice or the review of one's designs from accomplished experimenters outside of one's own research group can be a productive step, particularly when seeking to accommodate imperfect zero-gravity in experiment design.

Re-orienting maneuvers of the vehicle during the mission can also create unwanted accelerations. A researcher may consider working with the vehicle provider or flight manifesting organization early in the process to assure the experiment is manifested on a mission with the necessary maneuvering, or absence of maneuvering, and perhaps also the optimal placement of the experiment within the payload section. Some maneuvers may be necessary on descent, but others may be avoidable.

\section{VIBRATION}

Design for vibration is an interesting step at this stage. Until rockets are flying full missions and such things are actually measured, the vibration spectra and amplitudes supplied, if at all, are estimates. Even experience with designing for vibrations of an orbital launch is not directly applicable because a suborbital flight requires so much less energy than an orbital launch, regardless of air-launch, horizontal take-off, or vertical launch. Current design choices to accommodate vibrations are just the common elementary steps-nylon stop nuts, Loctite, multistrand instead of single-conductor wire, and similar. To date, in seven Armadillo launches and one Near-Space balloon-dropped glider flight (to develop upper-stratospheric parabolic flight capability), the only vibration related failure that has been encountered is a solder joint broken during the hour-long drive from a hotel in Truth or Consequences, NM, to the vertical launch facility at New Mexico Spaceport America. The experiment was resting on the floor in the back of a mid-sized SUV. No effort had been made to provide padding, so solving the problem on subsequent launches is simple - pad the floor or have someone hold the payload on their lap during the drive. This ground-transportation vibration failure suggests that the most severe vibrations that a next-gen suborbital payload may face are in the shipping from the experimenter's laboratory and delivery to the launch site. As such, care in packing the payload for air or ground shipping to the flight provider, spaceport for launch, or combined systems testing is recommended. The rocket flight may be the gentlest motion your experiment sees.

\section{INTERFACING AND INTEGRATION}

Most flight providers have at least a draft Payload User's Guide (PUG) online presently describing interfacing choices and requirements. Early experimenters may find changes are implemented as a launch date nears. That is, the early payloads are also the early experiences for the flight providers and thus, it is reasonable to expect that the providers may find important improvements will be necessary. In effect, experiences with early researchers are one part of how the providers will perfect their PUGs. In the early experiences of the Purdue program, a variety of approaches by flight providers have been encountered, presumably because of wide variations in vehicle development progress, staffing levels, and financing. Regardless, frequent communication is naturally found to be the key to effective progress. Planning for travel to the flight provider for an early interfacing visit and for a combined systems test would be wise. There has been no involvement with a payload integrating or manifesting company in the Purdue suborbital programs on which to report.

When preparing for travel to a launch, consider the drive from the launch site to the 
nearest hardware or home store. As rocket launches and populated areas historically have not been close together, you may need to pack more supplies, tools, spares, and similar items than you might be accustomed to taking to a parabolic aircraft flight campaign.

\section{LAUNCH OPERATIONS}

Researchers, especially preliminary researchers with a flight provider beginning commercial operations, should get long- and short-term schedule information from the flight provider and should then prepare to be adaptable. The industry is an emerging industry, not a mature industry, so expect changes as your flight provider's knowledge and experience grows with each test flight. For example, pre-launch fueling times may change; order of operations may change from one flight to the next and similar in these early days. So in these first years of operations, the procedures at a second launch may differ from those at your first launch with the same company. Thus, as with integration above, frequent communication will prevent surprises. Make sure communication is a priority on your end.

Researchers will also need to follow safety rules at a launch site. This seems obvious, but when excited for an experiment on launch day, forgetfulness can ensue. Various rules may be from the Federal Aviation Administration (FAA), insurance company, local fire safety, air traffic control, etc. Rules are not subject to alteration by your flight provider, so don't hassle the flight provider about them. Safety briefings the day before launch are common to review safety and operational steps. Pay close attention to the researchers' responsibilities and duties - in a launch emergency your duty is likely to stay in a bunker and not complicate things. Safety at remote sites may also include understanding if you are to supply your team's drinking water or if that is available at the launch site.
Rocket launches involve a lot of waiting on the part of the researcher. Bring plenty of things to read, manuscripts to edit, exams to grade, source code to debug, etc., as remaining calm will help you make better decisions if needed. Another step in preventing frustration is to prepare for the weather. Examine temperature extremes, which are to be expected at the launch site, and pack all proper apparel. Insist that your team members do the same.

\section{ACKNOWLEDGEMENTS}

The experiences reported above are the result of foresight and support of a number of organizations. Purdue University has supported the author's zero-gravity flight experiment designbuild-test teaching since 1996. John Gedmark, a co-founder of the Commercial Spaceflight Federation, catalyzed the author's entry into the commercial suborbital field and also the earliest flight test collaborations mentioned above. The Blue Origin payload is built with support from an Early Concept Grants for Exploratory Research (EAGER) grant from the National Science Foundation. The author gratefully acknowledges support from or collaborations with, alphabetically, Armadillo Aerospace, Blue Origin, Exos Aerospace, Masten Space Systems, NASA Flight Opportunity Program, National Science Foundation (EAGER grant 0940678), NorthropGrumman, and XCOR Aerospace.

\section{REFERENCES}

Collicott S (2011) Purdue student experiment and education in various low-gravity flight methods. In 49th AIAA Aerospace Sciences Meeting Including the New Horizons Forum and Aerospace Exposition, 4-7 January 2011, Orlando, FL, AIAA-2011-538, p 1-12

Stern SA (2013) Commercial spaceflight companies will revolutionize space science. Scientific American 308(4): 69-73 